\title{
Administration of Purwoceng (Pimpinella alpina Molk) Improves Oxidative Stress Biomarker Following UVC Irradiation in Spargue-Dawley Male Rats
}

\author{
Taufiqurrachman Nasihun ${ }^{1}$ and Eni Widayati ${ }^{2}$ \\ 'Department of Biochemistry, Medical Faculty of Sultan Agung Islamic University, Semarang, Central Java, \\ Indonesia \\ 2Department of Chemistry, Medical Faculty of Sultan Agung Islamic University, \\ Semarang, Central Java, Indonesia
}

\begin{abstract}
Introduction: UVC may induce oxidative stress mediated by ROS. Pimpinella alpina Molk (PaM) have been utilized by aging male as rejuvenation remedy. Objective: To elucidate the PaM effect on oxidative stress biomarker in rats. Methods: 25 of Sprague-Dawley male rats were divided into 5 groups, PaM with a dosage of 50, 100, and $150 \mathrm{mg}$ were administered during 15 days to evaluate the biomarker of oxidative stress following UVC irradiation for 30 minutes beforehand. The oxidative stress biomarkers were measured by TBARS and FRAP assay respectively. Results: Post Hoc analysis demonstrated that MDA and 8-OHdG concentration in PaM group were significantly lower $(p<0.001)$, otherwise the concentration of TAC in PaM group were significantly higher, $p<0.001$. Conclusion: Administration of PaM with 50, 100 , and $150 \mathrm{mg}$ dosage capable of improving oxidative stress biomarker in Sprague-Dawley male rats.
\end{abstract}

Keywords: MDA, 8-OHdG, Oxidative Stress Biomarker, Pimpinella alpine Molk, UVC

\section{Introduction}

The ultraviolet light coming from sun consists of ultraviolet A (UVA, 315-400 nm), UVB (280-315 $\mathrm{nm})$, and UVC (220-280 nm). Virtually, UVC due to its length of wave does not occur at the earth's surface because they are completely absorbed in the stratosphere by oxygen producing ozone ${ }^{1,2}$. However, in population UVC particularly from fluorescent lamps with a primary spectral peak of $254 \mathrm{~nm}$ commonly utilized as disinfection in a number of areas of waste water treatment to milk pasteurization ${ }^{3}$. Various data indicated that UVC has efficacy against a range of microorganisms including bacteria, viruses, fungi and protozoa ${ }^{3}$. Nevertheless, extraneous emission of UVC may affect the biological system by enhancing of free radical and may induce lipid peroxidation, oxidative stress, DNA fragmentation, cellular damages, degenerative diseases, and eventually aging 4 . Purwoceng (Pimpinella alpina Molk; PaM) is a plant that traditionally used as rejuvenation remedy and to enhance vitality in men of 40 years old or above ${ }^{5}$. Unfortunately, the effects of PaM to decrease lipid peroxidation and prevent cellular oxidative stress remain unclear.

\footnotetext{
*Author for correspondence

Email: taufiq_rn@yahoo.com
} 
To date, studies about PaM is extended to its effect on level of Testosterone (T), Luteinizing Hormone (LH), Follicle Stimulating Hormone (FSH) ${ }^{6}$, cGMP, Nitric Oxide Synthase (NOS) ${ }^{7}$, muscle strength, physiological organ function ${ }^{8}$, increased in $\mathrm{BCl}_{2}$ and inhibition of apoptosis in prostate and penis cells ${ }^{5}$. These various effects were attributable to stigmasterol as androgen precursor contained in PaM. Stigmasterol can be converted to $\mathrm{T}$ in peripheral tissues, and stimulate the increase in muscle mass and masculinity in men ${ }^{9}$. Refer to this argument; most previous studies were merely focused on PaM effect in masculinity traits such as vitality, muscle strength, erection, and apoptosis. Although, decrease in apoptosis of cellular penile and prostate purports the postponement of aging, however, it was not through PaM capacity as antioxidant, instead of through hormone replacement. In addition to stigmasterol, PaM also contains flavonoid ${ }^{7}$, an overwhelming antioxidant from plants which could neutralize Reactive Oxygen Species (ROS) when ingested. The effect of flavonoid of PaM is capable of reducing cellular damages resulted from oxidative stress, which in turn inhibits the biological aging process. Based on these arguments, $\mathrm{PaM}$, therefore, has double potencies to delay aging through both mechanisms of hormone replacement and oxidative stress attenuation, however, the latter needs evidence.

The most popular aging theory and accepted by the majority of scientists worldwide is free radical theory proposed by Denham Harman in $1956^{10}$. The free radical theory is one among other theories that could explain how aging process occurs in human. According to this theory, biological aging is caused by cellular oxidative stress resulted from an increase in prooxidant levels, such as $\mathrm{O}_{2}{ }^{\circ}, \mathrm{OH}^{\circ}, \mathrm{ROO}^{*}, \mathrm{H}_{2} \mathrm{O}_{2}, \mathrm{NO}$, and $\mathrm{ONOO}^{-}$are collectively named as RONS ${ }^{11}$, exceeding the antioxidant capacity in the body. Physiologically, any elevation of RONS level is followed by increase proportionally in the synthesis of first line antioxidants like superoxide dismutase (SOD), Glutathione Peroxides (GPx), and catalase (Cat), to prevent cellular damages caused by RONS ${ }^{11,12}$. A second line antioxidant also exists in the body, either in type of water or lipid soluble, such as ascorbic acid, tocopherol, beta carotene, flavonoid, etc., to support first line antioxidant capacity. The second line antioxidants even play a key role in delicate equilibrium between oxidation and anti-oxidation in living systems ${ }^{13,14}$. Individual antioxidant capacity can be determined by testing for SOD, GPx, Cat, etc., whilst Total Antioxidant Capacity (TAC) can be assessed by the cumulative effect of all antioxidant present in plasma ${ }^{15}$. Infection, inappropriate lifestyle, and chemical pollutant (xenobiotic) may lead to pro-oxidant outweighs antioxidant resulting in a prooxidant-antioxidant imbalance, and generates oxidative stress ${ }^{16}$. Owing to oxidative stress, cellular damages may occur particularly in phospholipid bilayer membranes and in both nucleus (nDNA) and mitochondrial DNA (mtDNA). The membrane damages are resulted from the reaction between ROS and unsaturated fatty acid membrane to form radical proxy (ROO), followed by formation of malondialdehyde (MDA) due to a reaction of $\mathrm{ROO}$ and unsaturated fatty acid in the same membrane ${ }^{16}$. The reaction between ROS and unsaturated fatty acids is facilitated by the weakness of methylene carbon-hydrogen bonds in membrane consist of unconjugated double bond that is separated by methylene group ${ }^{16}$. On the other hand, the DNA damages have resulted from $\mathrm{OH}^{\cdot}$ attack on guanine residues of DNA producing $8-\mathrm{OHdG}^{17,18}$. Considering 8 -OHdG is a major product and excreted in the urine without further metabolism, therefore, can be proposed as a biomarker of oxidative DNA damage in both nDNA and $\mathrm{mtDNA}^{18-20}$.

Pimpinella alpine Molk containing flavonoids can be hypothesized to inhibit oxidative stress and indeed biological aging. In the literature, the flavonoid is one out of the wide multitude of potential aging biomarker including MDA, SOD, Cat, GPx, Se, Mn, $\mathrm{Cu}$ and $\mathrm{Zn}$, vitamin $\mathrm{A}, \mathrm{C}$, and $\mathrm{E}^{21}$. The growing evidence demonstrated that flavonoid is able to suppress ROS production through a decrease in xanthin oxidase, debilitate RONS and cellular reaction, electron donor supply, and block oxidative propagative reaction. Blocking to the oxidative propagative reaction was done by chain breaking and strengthen cellular antioxidant through sparing effect with other antioxidant, as well as induce expression of endogenous antioxidant ${ }^{13,22}$. Clinical evidence also pointed out that flavonoid was able to prevent the development of colorectal cancer ${ }^{23}$, reduced risk of coronary heart disease, Parkinson disease, Alzheimer, inflammation and other pathologies related to decrease in ROS production ${ }^{24}$. Flavonoid 
was also proven capable of neutralizing free radical superoxide anion $\left(\mathrm{O}_{2}^{-}\right)$and peroxynitrite anion $\left(\mathrm{ONOO}^{-}\right.$ ), which in turn elevates Nitric Oxide (NO) level and gives a benefit of vascular dilation ${ }^{25}$. The decrease in ROS production, followed by an increase in endogenous antioxidant concentration provides cells experiencing oxidative stress an opportunity to self repair through Denovo formation. Taken together, administration of PaM will delay biological aging through prevention of cellular damages resulted from oxidative stress, which is mediated by an increase in lipid peroxidation. Opposite of these arguments, the objective of the present study is to investigate the effect of a PaM extract to decrease MDA and 8-OHdG levels and otherwise increase GPx level and TAC as a marker of declining cellular oxidative stress reflecting precocious biological aging ${ }^{26}$.

\section{Methods}

In the post test only control group design, 25 SpragueDawley male rats, age 3 months, weighing 250-300 grams, obtained from an Animal Experimental Development Unit of Gajah Mada University Yogyakarta were divided randomly into 5 groups (5 each) as follows: (1) Normal control group (Nor-C), orally treated with $2 \mathrm{ml}$ water, were not irradiated to UVC and PaM treatment. (2) Negative control group (Neg-C), orally treated with 2 $\mathrm{ml}$ water, exposure to UVC and were not treated with PaM. (3) 50 mg PaM group (PaM-50), (4) 100 mg PaM group (PaM-100), and (5) $150 \mathrm{mg} \mathrm{PaM}$ group (PaM150) were experimental groups, irradiated to UVC and orally treated with $50 \mathrm{mg} \mathrm{PaM}, 100 \mathrm{mg} \mathrm{PaM}$, and $150 \mathrm{mg}$ $\mathrm{PaM}$ respectively. All rats were kept in acclimatization for one week with environmental controlled temperature $\left(20-24^{\circ} \mathrm{C}\right)$, constant humidity (55-60\%), and controlled photoperiod ( $12 \mathrm{~h}$ light and $12 \mathrm{~h}$ dark) properties before beginning of the experiment. Normal balance diet and tap water were provided ad libitum. All rats except in Nor-C group were exposed to UVC at 7.00 am for 30 minutes at the distance of $20 \mathrm{~cm}$ during 15 consecutive days. PaM was administered orally immediately after UVC irradiation. At the end of the study, all rats were anesthetized with an intramuscular injection of $50 \mathrm{mg} /$ kg ketamine hydrochloride (Ketalar) and $2 \mathrm{ml}$ venous blood samples were collected by puncture of sinus orbitalis.

\subsection{PaM Extract}

Pimpinella alpine Molk was obtained from the market and extracted by Soxhlet methods from the whole plant with ethanol as a solvent.

\subsection{UVC Irradiation}

UVC irradiation was carried out using a fluorescent lamp (Philips, UK) that emitted $15 \mathrm{~W}$ of UV radiation between 190 and $280 \mathrm{~nm}$ (peak $254 \mathrm{~nm})^{27}$. The rats were exposed to UVC irradiation at a distance of $20 \mathrm{~cm}$ for 30 minutes daily.

\subsection{MDA Measurement}

MDA is formed at the end of long oxidative processes, generated from the reaction between ROS particularly $\mathrm{OH}^{*}$ and unsaturated fatty acid, accordingly can be used as an indicator of lipid peroxidation damage and oxidative stress. MDA level can be determined by spectrophotometry method that measures TBARS concentration. One millilitre of TBA reagent $(15 \% \mathrm{v} / \mathrm{v}$ trichloroacetic acid and $0.25 \mathrm{~N} \mathrm{HCl}$ ) was mixed with $500 \mathrm{ml}$ of supernatant and was treated in a boiling water bath for $15 \mathrm{~min}$. After cooling, the preparation was centrifuged at $1000 \mathrm{~g}$ for $10 \mathrm{~min}$. The supernatant was then removed, and the absorbance of the samples was measured at $532 \mathrm{~nm}$. The MDA concentration was expressed as nmol MDA/mg protein.

\subsection{8-OHdG Measurement}

In this study, the concentration of 8 -OHdG was measured using ELISA methods. It is a competitive enzyme immunoassay developed for rapid detection and quantization of 8 -OHdG in serum samples. ELISA kit was used produced from Abcam, containing a monoclonal antibody specific for 8 -OHdG. The principles of this method is to compare the quantity of 8-OHdG in the unknown sample with its absorbance of a known 8-OHdG standard curve. The unknown 8-OHdG samples or 8-OHdG standards are first added to an 8-OHdG/BSA conjugate pre-absorbed ELISA plate. After a brief incubation, an anti 8-OHdG monoclonal antibody is added, followed by a horseradish peroxidase (HRP) conjugated secondary antibody. ELISA was carried out in triplicate and in a blinded fashion, and the average value was used for statistical analysis. The kit has 
Table 1: Body weight, level of MDA, 8-OHdG, GPx, and TAC in Sprague-Dawley male rats

\begin{tabular}{lllllll}
\hline \multirow{2}{*}{ Variables } & \multicolumn{5}{c}{ Groups } & \multirow{2}{*}{ (ANOVA) } \\
\cline { 2 - 6 } & Nor- $\mathrm{C}(\mathrm{n}=5)$ & Neg-C $(\mathrm{n}=5)$ & $\mathrm{PaM}-50(\mathrm{n}=5)$ & $\mathrm{PaM}-100(\mathrm{n}=5)$ & $\mathrm{PaM}-150(\mathrm{n}=5)$ & \\
\hline MDA $(\mathrm{nmol} / \mathrm{mg})$ & $1.042( \pm 0.15)$ & $3.574( \pm 0.25)$ & $2.648( \pm 0.20)$ & $1.746( \pm 0.17)$ & $1.168( \pm 0.15)$ & 0.000 \\
8-OHdG (nmol/L) & $3.32( \pm 0.32)$ & $9.20( \pm 0.36)$ & $7.26( \pm 0.39)$ & $5.52( \pm 0.39)$ & $4.14( \pm 0.27)$ & 0.000 \\
GPx $(\mathrm{nmol} / \mathrm{L})$ & $90.84( \pm 3.76)$ & $31.76( \pm 7.03)$ & $45.42( \pm 4.60)$ & $68.98( \pm 7.03)$ & $87.48( \pm 4.60)$ & 0.000 \\
TAC $(\mathrm{nmol} / \mathrm{mg})$ & $1.780( \pm 0.12)$ & $0.562( \pm 0.04)$ & $1.036( \pm 0.06)$ & $1.172( \pm 0.07)$ & $1.552( \pm 0.09)$ & 0.000 \\
\hline
\end{tabular}

an 8 -OHdG detection sensitive range of $0.94 \mathrm{ng} / \mathrm{ml}-60$ $\mathrm{ng} / \mathrm{ml}$.

\subsection{GPx Measurement}

Glutathione peroxidase level was determined by the method of Paglia and Valentine, using a commercially available kit (Ransel; Randox Laboratories, UK). GPx catalyzes the oxidation of glutathione by cumene hydroperoxide. In the presence of glutathione reductase and NADPH, the oxidized glutathione is immediately converted to its reduced form with a concomitant oxidation of NADPH to NADP. The NADPHconsumption rate was monitored at $340 \mathrm{~nm}$.

\subsection{TAC Measurement}

TAC can be determined by FRAP that measures the cumulative effect of all antioxidant concentration in plasma. The principle of FRAP assay is measuring most reductans above a certain reduction potential. A Technicon RA 1000 system (Technicon Instruments Corporation, Tarrytown, NY) was used for the measurement of absorption changes that appear when the $\mathrm{Fe}^{3+}$-TPTZ2 complex is reduced to the $\mathrm{Fe}^{2+}$-TPTZ2 form in the presence of antioxidants. An intense blue color with absorption maximum at $593 \mathrm{~nm}$ develops. Measurements were performed at $600 \mathrm{~nm}$ after 4 minutes incubation. An aqueous solution of $500 \mu \mathrm{mol} / \mathrm{L} \mathrm{FeSO}_{4} \times 7$ $\mathrm{H}_{2} \mathrm{O}$ was used for calibration of the instrument. Three analytical portions of each sample were extracted, each extract was analyzed in triplicate, and results are given as reduced $\mathrm{TPTZ}-\mathrm{Fe}^{2+}$-complexes in $\mathrm{mmol} / 100 \mathrm{~g}$.

\subsection{Statistical Analysis}

ANOVA and Post Hoc test was adopted as statistical analysis in $95 \%$ of confidence interval or $p<0.05$ was considered statistically significant. All statistical analysis was done using computer programmes. This study has been approved by the Research Ethics Committee of Sultan Agung Islamic University Medical Faculty, Semarang, Central Java, Indonesia.

\section{Results}

After 15 days treatment of PaM, the result of MDA, 8-OHdG, GPx, and TAC concentration assessment can be seen in Table 1.

\subsection{MDA Levels}

The highest level of MDA was in Neg-C group, followed by a group of PaM-50, PaM-100, PaM-150, and the lowest was in Nor-C group. ANOVA statistical analysis showed that there was a significant difference between groups, $\mathrm{p}<0.001$. Moreover, Post Hoc test indicated that MDA level in Neg-C group was significantly higher compared to Nor-C group, $\mathrm{p}<0.001$. Malondialdehyde levels in a group of PaM-50, PaM-100, and PaM-150 were significantly lower compared to Neg-C group, $\mathrm{p}<$ 0.001 . In contrary, the level of MDA in group of PaM50 and PaM-100 was significantly higher compared to Nor-C group, $\mathrm{p}<0.001$. Whereas the MDA levels in group PaM-150 was not significantly different compared to Nor-C group, $\mathrm{p}=0.308$ (Figure 1).

\subsection{8-OHdG Levels}

The lowest level of 8-OHdG was occurred in Nor-C group, followed by PaM-150 mg, PaM-100 mg, PaM-50 $\mathrm{mg}$ respectively, and the highest was in $\mathrm{Neg}-\mathrm{C}$ group. One-way ANOVA statistical analysis demonstrated that there was a significant difference amongst groups, $\mathrm{p}<0.001$. Furthermore, Post Hoc analysis showed that concentration of $8-\mathrm{OHdG}$ in Neg-C group was significantly higher compared to Nor-C group, $\mathrm{p}<$ 0.001 . The level of 8-OHdG in PaM-50, PaM-100, and PaM-150 groups was significantly lower compared with Neg-C, $p<0.001$. Whereas, 8-OHdG levels in PaM50 and $\mathrm{PaM}-100$ groups compared with Nor-C group 
was significantly higher, $\mathrm{p}<0.001$. Likewise, the level of 8 -OHdG in PaM-150 compared with Nor-C group was lower significantly, $\mathrm{p}<0.005$. The level of 8 -OHdG in PaM-50 was significantly higher compared with PaM-100 and PaM-150, p $<0.001$, as well as the level of 8-OHdG in PaM-100 compared with PaM-150, p < 0.001 (Figure 1).

\subsection{GPx Levels}

As seen in Table 1, the highest level of GPx was in Nor-C group, followed by a group of PaM-150, PaM-100, and PaM-50 respectively, and the lowest was in Neg-C group. The result of one-way ANOVA statistical analysis indicated that there was significant difference amongst groups, $\mathrm{p}<0.001$. Post Hoc test pointed out that GPx levels in Neg-C group was lower significantly compared to Nor-C group, $\mathrm{p}<0.001$. Otherwise, the GPx level in group of PaM-50, PaM-100, and PaM-150 was significantly higher compared to Neg-C group, $\mathrm{p}<0.001$. Otherwise, the GPx level in group of PaM-50, PaM-100, and PaM-150 was significantly lower compared to Nor-C group, $\mathrm{p}<0.001$. The GPx level in PaM-50 group was significantly lower compared to group of PaM-100, and PaM-150, $\mathrm{p}<0.001$ and $<0.050$ respectively. Likewise, the GPx level in a group of PaM-100 was significantly lower compared to PaM-150 group, $\mathrm{p}<0.001$ (Figure 1).

\subsection{TAC Levels}

The highest level of TAC was in Nor-C group, followed by a group of PaM-150, PaM-100, and PaM-50 respectively, and the lowest was in Neg-C group. Oneway ANOVA statistical analysis indicated that there was a significant difference amongst groups, $\mathrm{p}<0.001$. Post Hoc test indicated that the TAC level in Neg-C group was lower significantly compared to Nor-C group, $\mathrm{p}<$ 0.001 . The TAC level in group PaM-50, PaM-100, and PaM-150 was significantly higher compared to Neg-C group, $\mathrm{p}<0.001$. In contrary, the TAC level in a group of PaM-50, PaM-100, and PaM-150 was significantly lower compared to Nor-C group, $\mathrm{p}<0.001$. The TAC level in PaM-50 group was significantly lower compared to group of PaM-100, and PaM-150, p $<0.050$ and $<0.001$
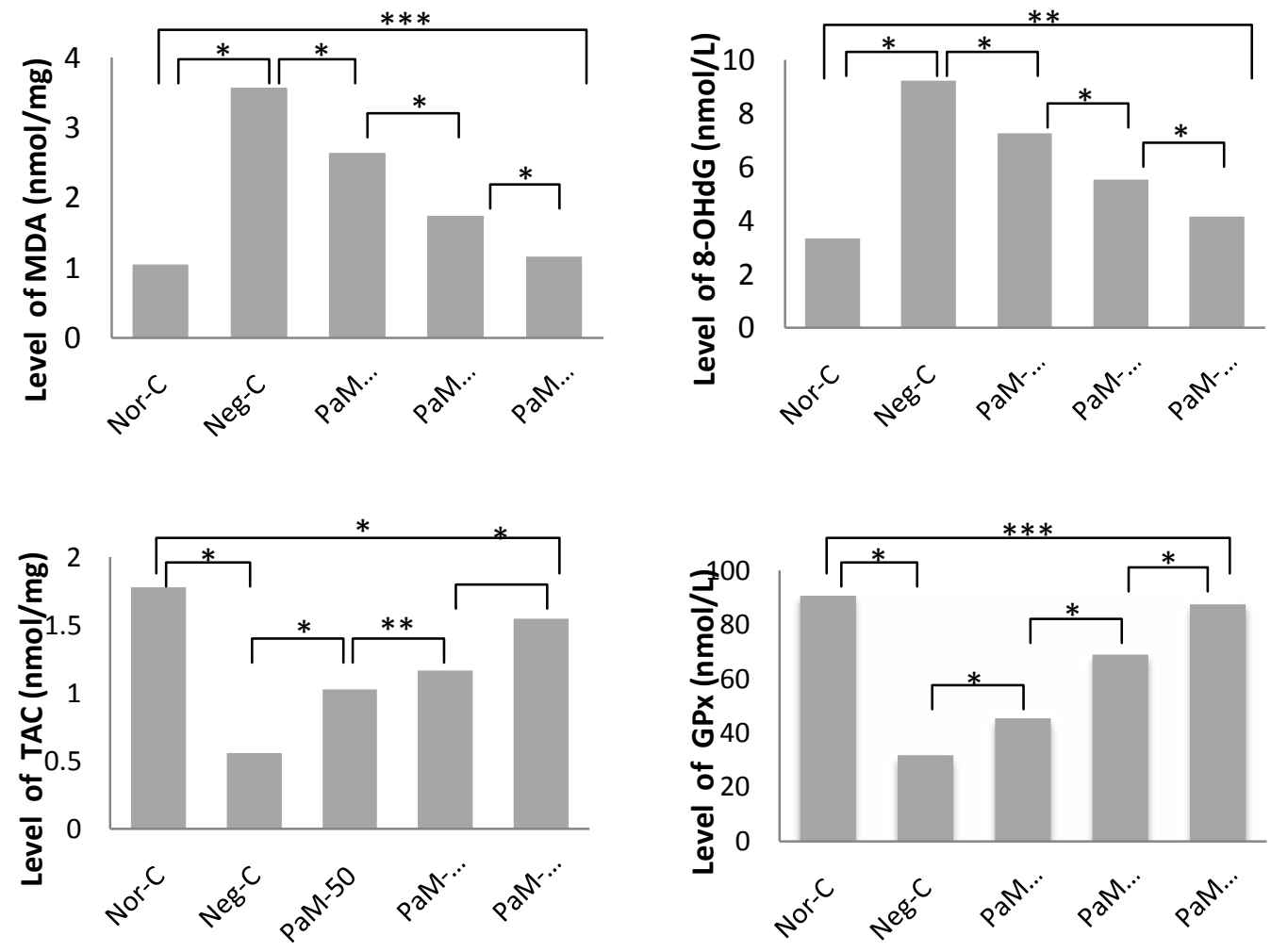

Fig. 1. Level of MDA, 8-OHdG, TAC, and GPx following UVC irradiation. Post Hoc test: ${ }^{*} p<0.001 ;{ }^{* *} p<0.005 ;{ }^{* * *} p>0.05$. 
respectively. Likewise, the TAC level in a group of PaM100 was significantly lower compared to PaM-150 group, $\mathrm{p}<0.001$ (Figure 1).

\section{Discussion}

There are growing evidence that biological effects of ultraviolet irradiation, including UVC are DNA damage, mutagenesis, cellular senescence, and carcinogenesis. These effects are in part mediated by ROS, the production of which is stimulated by UV irradiation of cells and tissues ${ }^{4}$. In the present study, irradiation of 15 watt fluorescent lamp as a source of UVC light that emits $5 \mathrm{~J} /$ $\mathrm{cm}^{2}$ was used to generate ROS in Sprague-Dawley male rats $^{26}$. Ultraviolet $C$ irradiation on rats was performed during 30 minutes daily at the distance of $20 \mathrm{~cm}$ have been proven capable of increasing level of MDA and 8-OHdG, and concurrently with decreased in the level of GPx and TAC in plasma. It was demonstrated by the increase in the level of MDA and 8-OHdG and decrease in GPx and TAC levels significantly in the negative control group compared with normal control group (Figure 1). These results suggest that UVC irradiation could induce ROS production in rats and lead to perturbation of prooxidant and antioxidant balance, in which the oxidant amount was outweighing the antioxidant defense. These findings are corroborated by the study of Santos et al. in which UVC was able to induce the generation of ROS, lipid peroxidation (TBARS), DNA damage, and reduced SOD enzyme activity ${ }^{28}$. According to this finding and its regression analysis, the authors suggested that biological damage was induced by UV irradiation on bacteria is wavelength dependent and revealed that inactivation of cellular bacteria by UVC was caused by the increase in ROS level together with DNA damage. The similar result comes from the study was reported by Hassanpour in horses, indicated that between MDA and antioxidant GPx, SOD, CAT, TAC, Vit E, Se, and hemoglobin have strong negative correlation ${ }^{29}$. The study reported by Yoshihisa et al., also showed that UVC irradiation was evidenced to increase the production of ROS such as superoxide $(\mathrm{O} 2)$, peroxide $\left(\mathrm{H}_{2} \mathrm{O}_{2}\right)$, and hydroxyl radical $(\mathrm{OH})$ in the keratinocytes ${ }^{27}$. The study of Fazeli et al., in seminal plasma also indicated that increase in MDA level was invariably followed by a decrease in the level of $\mathrm{TAC}^{30}$. Moreover, in clinical study was done by Kaya et $a l .$, in patients with coronary artery disease also showed an inverted correlation between 8-OHdG and MDA level and ubiquinol-10/ubiquinone-10 ratio respectively ${ }^{31}$. Interestingly, in Kaya study aside from a positive correlation between 8 -OHdG and MDA, a positive correlation also happened between 8-OHdG with GPx level. Regarding the GPx level, the result of the present study differed, because UVC irradiation increased 8-OHdG and MDA levels significantly, at the same time followed by decreased GPx level. To that difference, result may be attributable to compensatory regulatory response to oxidative stress related to oxidant-antioxidant defense mechanism ${ }^{31}$. Another study in the reproductive area proposed by Torres et al., also demonstrated that UVC irradiation was able to increase lipid peroxidation measured by TBARS in sperm membranes and reduced sperm motility in healthy men ${ }^{4}$. These previous studies imply that irradiation of UVC is able to induce oxidative stress which can be characterized by an increase in MDA and 8-OHdG and decrease in GPx and TAC level of plasma. The result of the present study supports this conclusion.

After PaM treatment, the concentration of MDA and 8-OHdG in the experimental groups of PaM-50, PaM100 , and PaM-150, was decreased significantly relative to negative control group. On the other hand, remain in the same experimental group's TAC and GPx levels were increased significantly compared to negative control group. The decreased in MDA and 8-OHdG levels following PaM treatment were attributable to flavonoids, a substance which is contained in PaM. Flavonoids are polyphenolic compounds found ubiquitously in human diets such as cereals, tea, wine, vegetables, and medicinal plants like as PaM and other photosynthesizing cells ${ }^{32}$. Flavonoids are characterized by two or more aromatic rings, each bearing atleast one aromatic hydroxyl and connected with a carbon bridge ${ }^{33}$. This bridge consists of three carbons that combine with oxygen and two carbons of one of aromatic rings (A rings) to form a third 6 member rings ( $\mathrm{C}$ ring). Until to date there are atleast 200 different types of flavonoids have been identified and their main effects were antioxidant, anti-inflammation, and cyto-protective ${ }^{34}$. The biological actions of flavonoids as an antioxidant have been proven by RiceEvan and coworkers in $1996^{35}$, through their ability to scavenge reactive species or through their influences on 
the intracellular redox status ${ }^{36}$. The study was proposed by Fremont et al. demonstrated that flavonoid was able to decline lipid peroxidation (marked by MDA level) in rats fed diet enriched in either polyunsaturated fatty acid or mono unsaturated fatty $\operatorname{acid}^{37}$. The study was reported by Li et al. also indicated that flavonoid derives from Flostrollii (Chinese tea) capable of scavenging different reactive oxygen species, including superoxide anion $\left(\mathrm{O}^{-}\right.$ ) , hydroxyl radical $\left(\mathrm{OH}^{\bullet}\right)$, lipid-derived radicals $\left(\mathrm{R}^{*}\right)$, and singlet oxygen $\left({ }^{1} \mathrm{O}_{2}\right)$ measured by Chemiluminescence technique ${ }^{38}$. The limitation in the $\mathrm{Li}^{38}$ study didn't investigate either TAC or antioxidant enzymes such as SOD, Cat, and GPx, accordingly could not evaluate prooxidant and antioxidant balance status. However, this limitation was answered by another in-vitro study carried out by Yasui et $a l^{39}$.This study pointed out that caffeic acid phenethyl ester (CAPE), a type of flavonoid ascribe to propolis was proven to suppress ROS production assessed by nitrobluetetrazolium (NBT) in 3T3-L1 cell during differentiation to adipocytes significantly in a concentration-dependent manner. Concomitantly, treatment of caffeic acid phenethyl ester (flavonoid) also significantly increased superoxide dismutase (SOD) activity in 3T3-L1 cells. Based on these results, the authors conclude that flavonoid can attenuate oxidative stress in 3T3-L1 differentiation to adipocytes, mediated partly by increased SOD production ${ }^{39}$. The later study is in agreement with the present study; PaM treatment was able to decrease MDA level and concurrently increased TAC level of plasma. Taken together, all data as mentioned above demonstrated that flavonoids, a cluster of compounds derived from plants including in PaM have an anti-oxidative potential effect mainly due to their redox properties, which can play an important role in neutralizing free radicals, quenching singlet and triplet oxygen species, and decomposing peroxides ${ }^{35}$.

However, there is growing evidence that using antioxidant to overcome oxidative damage in the whole organism and to diminish oxidative stress, no successes have been achieved. Meta-analysis of the major randomized clinical trials using antioxidant intervention for the treatment of cardiovascular and degenerative diseases revealed no beneficial effect by the various antioxidants treated ${ }^{40,41}$. There are several possible causes underlying this phenomenon. Firstly, the possible cause is the chemical nature of ROS. Oxygen radicals and other oxygen reactive metabolites are short-lived species capable of interacting, in high rate constants, with biological targets present in their immediate surroundings. Therefore, to scavenge these radicals, the antioxidant molecules should be located at the site of the ROS production in high concentration and continuously, in order to compete with the biological targets for the reactive species, and thus to protect them. Secondly, the possible cause is a large variety of ROS are produced on biological site of cells, thus to overcome the whole spectrum huge antioxidant is needed. In this circumstance, the interaction between antioxidant molecules and the radicals can neutralize the radical activity mediated by an electron donor from antioxidants to radicals. The third possible cause is TAC in plasma has no correlated with TAC of cells and tissues and doesn't reflect capability of tissues to cope with stress oxidative $^{42}$. It is possibly associated with tight regulation of intracellular TAC, that unable to changed despite the low weight antioxidant molecules are loaded. Invitro study was proposed by Koren et al., indicated that supplementation of low molecular weight antioxidant in HaCaT, Caco-2, PC3 and Hep3B culture cells unable to enhanced total antioxidant capacity ${ }^{41}$. Nevertheless, modulation of TAC remain possible if either very high concentration of low weight antioxidant molecules is loaded or polyphenol in low concentration.

Unfortunately, loading with very high level of isolated low weight antioxidant molecule is not impossible to stimulate oxidative stress and cellular damages due to excessive production of pro-oxidant. For example, administration of high doses of vitamin C $(500 \mathrm{mg} / \mathrm{d})$ to 30 healthy individuals caused an increase in oxidative damage in the DNA (indicated by an increase in 8-oxoadenine) from lymphocytes, suggesting prooxidative effects at elevated doses ${ }^{43}$. In another study, supplementation with vitamin $\mathrm{E}$, vitamin $\mathrm{C}$, and Q10 were failed to reduce oxidative DNA damage (indicated by the unchanged excretion rate of 8 -OHdG) in smokers $^{44}$. Another likelihood of pro-oxidant effect in high dose administration of isolated low molecular weight may be due to their reaction with beneficial levels of ROS, normally required for optimal cellular function ${ }^{13}$. Likewise, consumption at high dose of flavonoids can also induce a pro-oxidant effect, particularly in the present of transition metal such as copper and iron ${ }^{13}$. Study from De Marchi and co-workers indicated that quercetin at high 
dose $(50 \mu \mathrm{M})$ can potentiate superoxide radical $\left(\mathrm{O} 2^{*-}\right)$ generation within isolated mitochondria and cultured cells ${ }^{45}$. In another study reported by Robaszkiewicz and co-workers showed that quercetin at low dose (0.1-20 $\mu \mathrm{M})$ have an antioxidant activity, meanwhile at high dose $(>50 \mu \mathrm{M})$ displayed pro-oxidant activity marked by decreased in cell survival and viability, thiol content, TAC, and activities of SOD, Cat, and glutathione S-transferase ${ }^{46}$. Therefore, based on the various studies as aforementioned above take an antioxidant derive from plant flavonoid is the incontestable choice.

Aging is inevitable for every human, however, partly will undergo premature aging; never reach their maximum lifespan, accelerated by degenerative diseases, and socalled secondary aging ${ }^{47}$. On the other hand, people might achieve their maximum lifespan, free from degenerative diseases, and therefore able to reach their maximum lifespan, and named primary aging ${ }^{11,47}$. Maximum lifespan is the maximum time of species and determines the duration of species can survive. For instance, human species have maximum time is 122 years, whereas mouse and rats have maximum time only 3 and 4 years respectively ${ }^{11}$. Nowadays, the majority of people are able to attain their average lifespan only in the range of 73-78 years, albeit virtually their maximum life spans are 122-140 years ${ }^{11}$. The largest causes of inability to reach the maximum lifespan are degenerative diseases such as type 2 diabetes mellitus, cancer, stroke, poor cognition, etc. The repercussion of suffering from degenerative diseases, the left-over life of aging people bear with physical frailty $(28,6 \%)$, immobility $(20,4 \%)$, low agility $(14.2 \%)$, and poor cognition $(10.6 \%)^{11}$. The clinical implication of these conditions includes falls, fractures, and aging people were unable to perform their daily activities. Therefore, they need special nursing; unfortunately, it is very expensive, either in hospital or at home ${ }^{48}$. In this instance, the majority of people and their families, even insurances of the countries unaffordable to support funding to nurse. An illustration coming from the USA can be posed, cost spending for nursing aging people who experiencing immobility in the year of 2000 have achieved 76 billion USD ${ }^{11}$. This spending cost to be increased when aging people get 80 years or older. Based on these arguments, prevention or delay the appearance of degenerative diseases through appropriate life style constitutes prime priority. In addition, considering, the largest part of the pathogenesis of degenerative diseases are caused or associated with oxidative stress, therefore reduce oxidative stress with an oral antioxidant is a reasonable choice. Pimpinella alpine Molk is one among other antioxidant flavonoids that can be used to neutralize oxidant in the body. However, for clinical use particularly to delay aging, further clinical research is needed.

\section{Conclusion}

In line with the result of this study and aforementioned discussion, conclusion can be inferred that dosing of 50-150 mg of PaM for 15 days capable of improving oxidative stress biomarker which is characterized by decrease in MDA and 8-OHdG levels and increase in GPx and TAC levels in Sprague-Dawley male rats, even in certain extent comparable to normal condition.

\section{Acknowledgment}

The author greatly appreciated to Yulianto as a laboratory staff who assisted in carrying out this study.

\section{Conflict of Interest}

The authors report no conflicts of interest. The authors alone are responsible for the content and writing of the paper.

\section{References}

1. Paz ML, Maglio DHG, Weill FS, et al. Mitochondrial dysfunction and cellular stress progression after ultraviolet B irradiation in human keratinocytes. Photodermatology, Photoimmunology \& Photomedicine. 2008; 24:115-22.

2. Ryu HC, Kim C, Kim JY, Chung JH, Kim JH. UVB radiation induces apoptosis in keratinocytes by activating a pathway linked to BLT2-reactive oxygen species. Journal of Investigative Dermatology. 2010; 130:1095-106.

3. Franzco SJD, Boptom AP, Swift S, et al. Efficacy and safety assessment of a novel ultraviolet $\mathrm{C}$ device for treating corneal bacterial infections. Clinical and Experimental Ophthalmology. 2011; 39:156-63.

4. Torres ERS, Abad C, Ero SP, et al. Effect of ultraviolet C irradiation on human sperm motility and lipid peroxidation. Int J Radiat Biol. 2010; 86:187-93. 
5. Taufiqurrachman. Decreased expression of caspase 3 in penis and prostate tissues of rat after the treatment with buceng (Pimpinella alpine Molk and Euricoma longifolia Jack). 2013; 22:14-7.

6. Taufiqurrachman. The effect of buceng extracts on androgen production in Sprague-Dawley male rats. Medical Journal of Indonesia. 2012; 21(1):29-31.

7. Suzery M. Efekpemebrianekstrak Purwocengterhadap IndikatorEreksi (Study experimental padatikusjantan Sprague Dawley yang dikastrasi). Disertasi Undip; 2012.

8. Caropeboka AM. Pengaruh Akar Pimpinellaalpina Koordterhadap Susunansyarafpusat. Bagian Farmakologi Dept. Fisiologidan Farmakologi Fakultas Kedokteran Hewan. IPB Bogor; 1976.

9. Granner DK. Hormones of the Gonads. In: Murray RK, Granner DK, Mayes PA, Rodwell VW,editors. Harper's Biochemistry 24thed. Appleton\& Lange/A simon \& Schuster Company; 2000. p. 566-70.

10. Beckman KB, Ames BN. The free radical theory of aging matures. Physiol Rev. 1998; 78:547-81.

11. de la Fuente M, Miquel J. An update of the oxidationinflammation theory of aging: the involvement of the immune system in oxi-inflamm-aging. Current Pharmaceutical Design. 2009; 15:3003-26.

12. Wang X, Sharma RK, Gupta A, et al. Alteration in mitochondria membrane potential and oxidative stress in infertile men: a prospective observation study. Iranian Journal of Reproductive Medicine. 2009; 7:29-34.

13. Bouayed J, Bohn T. Exogenous antioxidants double-edged swords in cellular redox state Health beneficial effects at physiologic doses versus deleterious effects at high doses. Oxid Med Cell Longev. 2010; 3:228-37.

14. Pandey KB, Rizvi SI. Plant polyphenols as dietary antioxidants in human health and disease. Oxid Med Cell Longev. 2009; 2:270-8.

15. Ko EY, Sabanegh ES, Agarwal A. Male infertility testing: reactive oxygen species and antioxidant capacity. Fertility and Sterility. 2014; 102:1518-27.

16. Ladiges W, Wanagat J, Preston B, Loeb L, Rabinovitch P. A mitochondrial view of aging, reactive oxygen species and metastatic cancer. Aging Cell. 2010; 9:462-5.

17. Yao QH, Mei SR, Weng QF, Zhang PD, Yang Q, Wu CY, $\mathrm{Xu}$ GW. Determination of urinary oxidative DNA damage marker 8-hydroxy-2'-deoxyguanosine and the association with cigarette smoking. Talanta.2004; 63:617-23.

18. Fukushima K, Murata M, Tsukimori K, Eisuke K, Wake N. 8-Hydroxy-2-Deoxyguanosine staining in placenta is associated with maternal serum uric acid levels and gestational age at diagnosis in pre-eclampsia. American Journal of Hypertension. 2011; 829-34.

19. Tarng DC, Huang TP, Liu TY, Chen HW, Sung YJ, Wei YH. Effect of vitamin E-bonded membrane on 8-hydroxy2'deoxyguanosine level in leukocyte DNA of hemodialysis patients. Kidney International. 2000; 790-9.

20. Donati A, Cavallini G, Bergamini E. Effects of aging, antiaging calorie restriction and in vivo stimulation of autophagy on the urinary excretion of $8 \mathrm{OHdG}$ in male Sprague-Dawley rats. AGE. 2013; 35:261-70.

21. Voss P, Siems W. Clinical oxidation parameters of aging. Free Radical Research. 2006; 40:1339-49.

22. Akhlaghi M, Bandy B. Mechanisms of flavonoid protection against myocardial ischemia-reperfusion injury. Journal of Molecular and Cellular Cardiology. 2009; 46:309-17.

23. Walle T. Methoxylated flavones, a superior cancer chemo preventive flavonoid subclass? Seminars in Cancer Biology. 2007; 17:354-62.

24. López OP, Martha L, Ceja C, Pérez MV, Pérez TH. Berries: improving human health and healthy aging, and promoting quality life-areview. Plant Foods Hum Nutr. 2010; 65:299-308.

25. Chen WS, Lee YJ,Yu YC, et al. Enhancement of p53mutant human colorectal cancer cells radiosensitivity by flavonoid fisetin. Int J Radiation Oncology Biol Phys. 2010; 5(77):1527-35.

26. Voss P,Siems W. Clinical oxidation parameters of aging. Free Radical Research.2006 Dec; 40(12):1339-49.

27. Yoshihisa Y, Rehman M, Shimizu T. Astaxanthin, a xanthophyll carotenoid, inhibits ultraviolet-induced apoptosis in keratinocytes. Experimental Dermatology. 2014; 23:178-83.

28. Santos AL, Oliveira V, Baptista I, Henriques I, Gomes $\mathrm{NCM}$, et al. Wavelength dependence of biological damage induced by UV radiation on bacteria. Arch Microbiol. 2013; 195:63-74.

29. Hassanpour A. Correlation of malondialdehyde and antioxidants of serum in the horses with strangles. Indian Journal of Fundamental and Applied Life Sciences. 2013; 3:327-34.

30. Fazeli F,Salimi S. Correlation of seminal plasma total antioxidant capacity and malondialdehyde levels with sperm parameters in men with idiopathic infertility. Avicenna J Med Biochem. Forthcoming 2016; e29736.

31. Kaya Y, Cebi A, Soylemez N, Demir H, Hakan Halp, Bakan E. Correlations between oxidative DNA damage, oxidative stress and co-enzyme Q10 in patients with coronary artery disease. Int J Med Sci.2012; 9:621-6. 
32. Cushnie TPT, Lamb AJ. Antimicrobial activity of flavonoids. International Journal of Antimicrobial Agents 2005; 26:343-56.

33. Beecher GR. Overview of dietary flavonoids: nomenclature, occurrence and intake. The Journal of Nutrition; 2003 Oct; 133:3248-54.

34. Rodrigues AMG, Marcilio FS, Muzitano MF, Therapeutic potential of treatment with the flavonoid rutin after cortical focal ischemia in rats. Brain Research. 2013; 1503:53-61.

35. Rice-Evans CA, Miller NJ, Paganga G. Structure antioxidant activity relationships of flavonoids and phenolic acids. Free RadicBiol Med. 1996; 20:933-56.

36. Pollard SE, Kuhnle GG, Vauzour D, Vafeiadou K, Tzounis $\mathrm{X}$, Whiteman M, Rice-Evans C, Spencer JPE. The reaction of flavonoid metabolites with peroxynitrite. Biochem Biophys Res Commun. 2006; 350:960-8.

37. Fremont L, Marie GT, Marie FP, Alain L. Dietary flavonoids reduce lipid peroxidation in rats fed polyunsaturated or monounsaturated fat diet.The Journal of Nutrition.1998; 128:1495-502.

38. Li H, Zhang MBS, Ma GBS. Radical scavenging activity of flavonoids from Trollius chinensis Bunge. Nutrition. 2011; 27:1061-5.

39. Yasui N, Nishiyama E, Juman S, Negishi H, Miki T, et al. Caffeic acid phenethyl ester suppresses oxidative stress in 3T3-L1 adipocytes. Journal of Asian Natural Products Research. 2013; 15:1189-96.

40. Etminan M, Gill SS, Samii A. Intake of vitamin E, vitamin $\mathrm{C}$, and carotenoids and the risk of Parkinson's disease: a meta-analysis. Lancet Neurol. 2005; 4:362-5.
41. Koren E, Zverev I, Ginsburg I, Kohen R. Supplementation with antioxidants fails to increase the total antioxidant capacity of several cell lines in culture. Biomedicine \& Pharmacotherapy. 2008; 62:179-88.

42. Berry EM, Kohen R. Is the biological antioxidant system integrated and regulated? Med Hypotheses. 1999;53:397401.

43. Podmore ID, Griffiths HR, Herbert KE, MistryN, nMistry P, Lunec J. Vitamin C exhibits pro-oxidant properties. Nature. 1998; 392:559.

44. Prieme H, Loft S, Nyyssonen K, Salonen JT, Potilsen HE. No effect of supplementation with vitamin E, ascorbic acid, or coenzyme Q10 on oxidative DNA damage estimated by deoxyguanosine excretion in smokers. Amn J ClinNuir. 1997; 65:503-7.

45. De Marchi U, Biasutto L, Garbisa S, Toninello A, Zoratti M. Quercetin can act either as an inhibitor or an inducer of the mitochondrial permeability transition pore: a demonstration of the ambivalent redox. Biochimicaet Biophysica Acta. 2009; 1787:1425-32.

46. Robaszkiewicz A, Balcerczyk A, Bartosz G. Antioxidative and prooxidative effects of quercetin on A549 cells. Cell Biol Int. 2007; 31:1245-50.

47. Huebschmann AG, Kohrt WM, Regensteiner JG. Exercise attenuates the premature cardiovascular aging effects of type 2 diabetes mellitus. Vascular Medicine. 2011; 16: 378- 90 .

48. Tinetti ME, Speechley M, Ginter SF. Risk factors for falls among elderly persons living in the community. $\mathrm{N}$ Engl J Med. 1988; 319:1701. 